\title{
The Guampedia experience Creating a community online historical and cultural resource
}

\author{
Shannon Murphy \\ Guampedia Foundation, Inc., Guam
}

\section{Introduction}

Guampedia (http://guampedia.com) is an online encyclopedia that developed as a community project. Guampedia is dedicated to creating an easily accessible, comprehensive and informational internet resource about Guam's history, culture and contemporary issues. It debuted in April 2008 as the island's first online encyclopedia which synthesises scholarly and indigenous considerations in a user-friendly framework (Figure 1). It is intended to spur critical thinking about the island's complex history.

The primary objectives of the Guampedia project revolve around preservation, access and education. Information about important events and people conveyed in accurate and well-written encyclopedia entries ensures the preservation of Guam's history and culture. An internet platform provides everyone with easy access to text, photographs, audio and video that might otherwise be difficult to locate. Locally produced material focused on the island's heritage educates schoolchildren and a worldwide audience, which strengthens local and global knowledge of Guam's traditional and contemporary society and culture. Dr Nicolas Goetzfridt (2006:340) defines Guampedia’s goal as:

... holistically describing its [Guam's] past and present, both locally and globally, in an electronic format that makes its heritage available to the world (and particularly to the American public whose influence in Guam remains an element of its own heritage) and to the local environment where it promises to make significant contributions to the island's educational, cultural and economic environments.

The Guam Humanities Council initiated the Guampedia project in 2002 and launched it online in 2008 with some 350 entries and approximately 900 photographs. In 2008, Guampedia became its own organisation, the Guampedia Foundation, with offices at the University of Guam in a professional affiliation with the Micronesian Area Research Center. Currently, the international community has access to an interactive, engaging and scholarly encyclopedic 


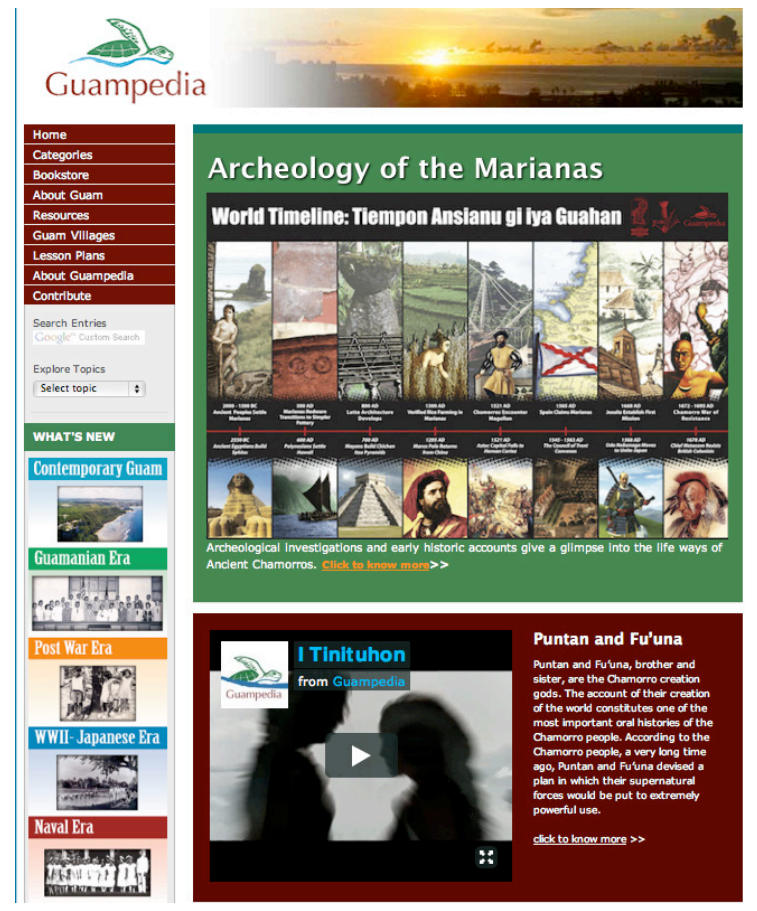

Figure 1. Homepage of Guampedia, Guam's online encyclopedia (August 2011).

online resource offering more than 680 entries, 2000 photos, about 15 videos, and 20 audio files describing Guam's culture and history.

Guampedia is intended to be a comprehensive reference work for students, advanced scholars and the public, including the federal government, investors and the press. The goal has been for Guampedia to be media rich, filled with historic and contemporary photos, video and audio. Information about those significant people, places, events and institutions that have shaped Guam is updated regularly, with each entry signed by its author(s). Guampedia will continue to be an evolving, dynamic project that will be updated and added to regularly as events unfold and technology allows.

The lessons learned during the evolution of Guampedia are presented here in the hopes that other island nations will consider the value of an online encyclopedia showcasing their cultures and societies. By sharing our experiences, Pacific Island communities will have the tools needed to create their own internet sites in the manner best suited to preserve and teach their natural and cultural heritage.

\section{The need for a community heritage resource}

An online encyclopedia such as Guampedia accomplishes a crucial mission. While the people of Guam embrace the global community that has emerged from the rise of technology, many vocalise their belief that it is increasingly important to preserve the culture of Guam's indigenous Chamorros. The island's unique history and information about local events, people and organisations should and can be available to everyone - from schoolchildren to adults, from local residents to newcomers, to people living around the world. Without efforts like this, these historical and cultural treasures might be lost to future generations, a tragedy for our ancestors, Micronesia and the Pacific. Guampedia helps Guam's culture survive by keeping the island's people informed and educated and bringing what is special about Guam to the world's attention.

Online accessible projects can be a needed bridge between traditional, customary and scholarly experts and the public. Oftentimes, those with expert knowledge do not have the time or the ability to share their information with the community by writing articles and books that are 
readily available to a public audience. Much of the scientific information produced by academics and environmental and cultural-resource managers is only published in specialised technical journals or in the grey literature housed in government offices. The valuable information held by traditional sources is often taught and passed down from generation to generation orally. An online encyclopedia is a venue that provides people with information that may never have been expressed in written form or may only have been presented in a technical manner.

Anyone with a computer and access to the internet can learn about a Pacific Island nation's history and culture through an online encyclopedia. Guampedia's target audience is students and teachers, visitors, Chamorros (those indigenous to the Mariana Islands) and Guamanians (peoples of Guam; see Eclavea 2010), both on and off-island. With an increasing number of islanders living abroad and the availability of computers in island school systems, online access to information is an extremely important educational tool. In addition, online encyclopedias are a valuable resource for the media, potential businesses and investors, and the federal government, in that they provide accurate information and save precious time in data collection. Guampedia offers a variety of ways for the community, both on and off-island, to learn about its homeland.

Through Guampedia, fact-checked, peer-reviewed and up-to-date information about Chamorro communities and ancient and contemporary data about Guam and the Mariana Islands is easily available and free. Encyclopedia entries typically serve as general, straightforward introductions to the topics, with readers guided to where they can find more in-depth information through either a reading list or links to further entries. Interpretive essays written by scholars are available for those wanting a deeper understanding about pertinent issues affecting Guam. Many topics include photos, drawings, illustrations, video and audio files. The multiple-media formats that can be produced on the internet allow for dynamic styles of expression, some of which better capture the data's significance, the receiver's imagination, or the traditional way of expressing that knowledge.

Accurate information has been a primary concern for the Guampedia Foundation. The Guampedia Project Author Manual (Guam Humanities Council 2004) offered this guideline for its contributors:

Accuracy, accuracy, and again accuracy! Do not reproduce errors that appear in older secondary sources.

Check every fact. Each person working with Guampedia has an obligation to generations yet unborn to dispel misinformation and to write without distortion.

The Guampedia manual further advised authors to: 'Be as specific as possible. Give precise information when you can ... If you know that an event took place in a particular village, include the community's name.' Another guiding principle has been to emphasise Guam: 'Every entry in Guampedia is being included because of its importance to Guam, and this fact should be reflected in the writing' (Guam Humanities Council 2004). Too often, historical and other sources have given the primacy of focus to others (such as colonising forces) or have only minimally included Guam and its peoples. This creates a variety of challenging issues for the island community. Guampedia aims to re-align such a non-localised focus to make the people and history of Guam the main focal point. This emphasis better meets the public desire for community-specific information and serves as an educational tool for island teachers and youth.

Guampedia is a growing repository of historical and cultural information. A motivating issue is the limited printing of island-centred materials; another is that much of what has been printed is at an academic level that is not readily digestible by the general public, specifically school-aged island children. Additionally, academic material is often issue- and time-specific, requiring a great amount of effort to fully understand the topic. Guampedia strives to balance 
maintaining the integrity of up-to-date expert knowledge and providing an accessible reading level, keeping in mind that a main goal is to have the online encyclopedia serve upcoming generations of the island's youth.

The public can offer critiques and corrections of Guampedia's online articles. At the bottom of each entry, readers are asked whether the information is useful and whether they have comments or questions. In the two years since the site was launched, Guampedia has had nearly 2000 responses. As a testament to Guampedia's role in filling a gap within the community, about $80 \%$ of the responses are from people saying thank you, that the online encyclopedia is a wonderful and amazing site, and similar submissions. Most of the other comments are from those looking for more information about the topics or additional entries. Three percent of the submissions are from people who offer corrections or dispute the information. The Guampedia staff responds to each of these comments.

\section{How to make an online encyclopedia}

The creation and up-keep of an online encyclopedia requires a dedicated community effort. As a first step, the Guampedia team created a mission statement to help keep the focus on the goals. The Guampedia Mission Statement is:

We believe that the future of our island is dependent upon an informed, educated citizenry. Scarce resources result in limited opportunities to learn and understand about Guam's unique history, culture, environment and present-day society. Guampedia exists to provide a comprehensive, accessible resource about Guam that will educate the global community and increase opportunities for the enlightenment of our people, allowing us to chart our destiny.

The mechanics involved in constructing such a large and public project can be complex. Presented here is a discussion of the four key points that need to be considered during the planning process. The points are:

1. Site content

2. Community participation

3. Internet technology

4. Cost and funding sources

\section{Site content}

The Guampedia team had to decide what the site would contain and how this would be organised for ease of use. To determine content, we first came up with a list of topical categories which could be broken down into smaller sections. Amended over the years, Guampedia now has categories covering: Art, Architecture, Body Adornment, Music and Food; Chamorro Culture; Economics and Commercial Development; Education; European Exploration, Trade and Scientific Studies; Health and Medicine; Historic Eras; Justice; Language; Natural Resources; Non-Chamorro Ethnicity; People; Politics and Government; Religion; Sports and Recreation; Transportation, Technology and Communications; Trends; Villages, Historic Places and Island Life; and Wars and Factors of Peace.

We then invited scholars and local experts from a variety of fields to help develop outlines of what to include in each of these broad categories to provide comprehensive coverage of the topic. For example, we asked Father Eric Forbes, a Capuchin scholar and historian, to help develop the Religion section. We asked Professor Rosa Palomo, the head of the Micronesian Language Institute and former Chair of the Chamorro Language Commission, to assist with 
outlining the Chamorro Language section. Several professors from the University of Guam's Micronesian Area Research Center (MARC) were invited to work on categories such as local art, politics, European exploration and trade, the history of wars that have affected Guam, and so on.

Next, we developed a timeline of Guam history to create a content grid. Based on archaeological and historical findings, the Guampedia Foundation developed this timeline:

- Ancient Guam (3800 years ago-1668)

- Spanish Era (1668-1898)

- US Naval Era (1898-1941)

- WWII/Japanese Era (1941-1944)

- Post-War Guam (1944-1950)

- Guamanian Era (1950-1970)

- Contemporary Guam (1970-present)

Once the grid was established, we decided on organisational principles to guide the length, style and content of the five types of entries, ranging from short basic entries to longer interpretive essays. We then developed standards, contracts and a writer's fee and invited people to submit text and photos for each topic.

The result is the set of 19 categories, most of which are broken down into subcategories, many further subdivided, and linked back to one another. Not all categories use the timeline, as some topics range over several time periods or are not applicable to such an organisational structure. The Religion category (see below) contains 10 subcategories, divided into 58 topical entries. For example, the Contemporary Guam section has six topics and the WWII/Japanese Era section presents three topics.

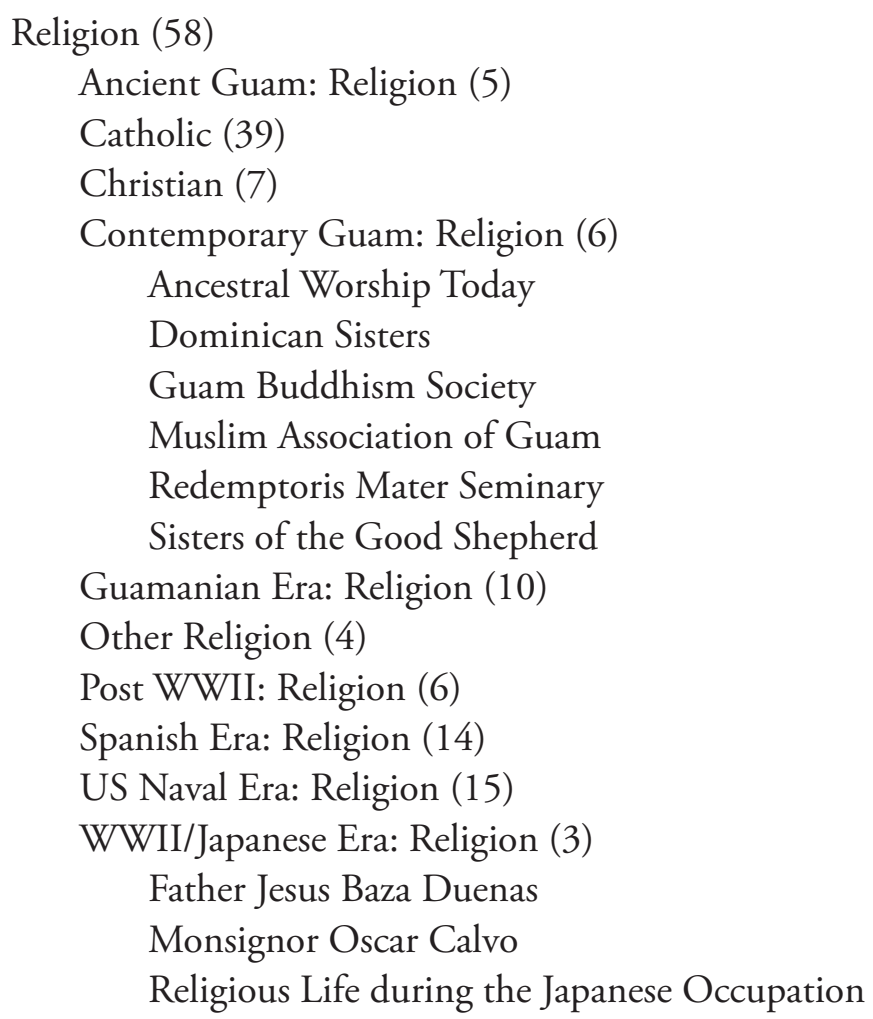


The homepage also links directly to overall information about Guam, educational lesson plans and interpretive essays. There is direct access to a bookstore and MARC publications, audio and photo galleries, information on Guampedia staff and contributors, and information on resources used by Guampedia. The audio gallery can include oral histories provided by the elders to preserve these older and experienced voices and musical performances. Visual documentation is provided in photos and the videos that present entire dances, re-enactments of legends, virtual tours of a location, and historical war footage.

\section{Community involvement: Organisers, contributors, advisors}

From its inception, the Guampedia team wanted Guampedia to be a community resource, created by and for the community. The team met with numerous agencies, institutions and organisations, including leaders of the public schools, the libraries, the museums, the legislature, the Governor, Guam's congressional office and the Catholic Church. We described our goals and asked for their input and support, and use of their resources. These groups were assured that this was a community effort with everyone working together to create something that we could all be proud of so that people on Guam and around the world could learn more about the island and its people.

Our next step was to list and contact the experts connected to each topic. Some of these experts were academics and researchers, others were community members with experiences to share, while others were keepers of traditional and cultural knowledge. We also identified in what publications or through which institutions we could find particular information. As the entries arrived, community members were chosen to fact-check, peer-review, advise and edit the documentation before it was placed online.

Today there is a permanent staff of three people: a managing editor, a content editor and a media editor. Guampedia relies on its volunteers, who form an Advisory Board, as its editorial team. Volunteer community members are educators, politicians, environmentalists, housewives, fishermen, economists, anthropologists, artists and others from every walk of life. To date, well over 100 Guamanians and Chamorros have participated in the Guampedia project by conducting research, writing entries, peer reviewing, fact checking or copy editing the entries and media. Authors are paid fees generated from grants for their research and writing.

\section{Technology}

Once the content was mapped out, the Guampedia team began talking to internet technology (IT) companies about the options available for a website that was user-friendly for both the site's visitors and its creators. Many online encyclopedias and comparable websites were examined and assessed for their strengths and weaknesses in serving their communities. An inspirational website was a New Zealand site called Te ara, a Maori term for pathway (www.teara.govt.nz). These evaluations allowed for a broader perspective of what best suited the Guam community and the available technology.

An important consideration in Pacific communities is the strength and capability of the local internet service provider. Many islanders pay by the minute for internet services and have only slow dial-up internet access. Complex entries containing numerous photos, maps, or even links can take several minutes to download and thus not be worth the time and cost required to wait for each page. Online encyclopedias in these island nations need to have simple entries that can be easily updated in the future when there is access to faster internet services.

An IT company thought to be the most capable of meeting Guampedia's specific needs was selected. Although not the lowest bidder, the company was chosen because the staff and community felt the most comfortable working with it. Trust is a very important consideration 
at this point of the development process. Additionally, it was decided that a top priority for this particular type of project was hiring a company that was proven to be able to provide a highquality result. Of course, Guampedia had its limitations and the final price was negotiated.

In 2002, when Guampedia was just starting, computer programmers had to be hired to design codes used in tailoring the website to look and work according to our desires and specifications. For example, if a navigation sidebar was desired, then it had to be programmed as a feature. If links to submit feedback or make contact with Guampedia were deemed necessary then these features required specific programming.

Despite the passage of only nine years, today's (2011) online environment is much different. During this period, computer programmers banded together to create universal internet programs that are more easily replicated. Now there is free, open-source software available on the web that has all the options an entity might envision for itself and its audience. An IT company is still needed to set up a website, but the process will not be as lengthy or as expensive as Guampedia experienced in its embryonic years. Guampedia is now using WordPress, free software available to all. For a minimal cost, Guampedia currently subscribes to services such as Flickr (www.flickr.com/) to store photos, Vimeo (http://vimeo.com/) to store video and Issuu (http://issuu.com/) to share large documents and books.

There are numerous other web options available to those creating an interactive website. These days, a site can be developed for very little money and then maintained for less than US $\$ 1000$ a year. Website developers may tell you otherwise, but the knowledge Guampedia has learned over the years is testimony to the fact that even quite large websites can be maintained with a annual small budget. Our staff of three, none 'techies', has learned to post entries, photographs, video and audio, and update our front page. This serves as an example that other Pacific Island communities can also accomplish these tasks without a great deal of technical knowledge or funding.

Guampedia is following the established technical and information standards of the National Initiative for a Networked Cultural Heritage's Guide to Good Practice in the Digital Representation and Management of Cultural Heritage Materials (www.nyu.edu/its/humanities/ ninchguide). ${ }^{1}$ By following these freely accessible standards, it is ensured that digital resources are compatible with each other now and in the future as technology evolves.

\section{Funding}

Finding the funding to initiate a project of the magnitude of Guampedia can be a strenuous experience, with many learning curves and challenges. First, a comprehensive work plan and feasible budget must be developed. Then, entities seeking funding have to accurately map out why their project is important and how capable their team is to people who have no knowledge about their culture, island area or project visions. Additionally, funding sources for the particular type of project that the particular type of organisation is qualified to apply for must be identified. Soon, one learns that some grants are only available to government agencies, for example, while others will only be awarded to non-profit organisations with federally recognised tax-exempt status. Guampedia, which developed from the ground up, advises building your organisation first, next creating a focused project work plan, and then looking for grants that match that particular phase of your project.

After submitting numerous grant applications to local and federal governments and to private organisations, Guampedia was successful in obtaining several federal grants from the US National Endowment for the Humanities (NEH) and the US Department of the Interior (DOI). As a US territory, NEH grants were available to Guam through the island's local humanities 
council. There are other NEH grants that US-based non-profit organisations can receive. As a United States commonwealth, the northern Mariana Islands can apply for assistance from NEH. However, the Federated States of Micronesia (FSM) and the Republic of Palau do not directly qualify for US NEH funding.

Locally, Guampedia was funded largely by the Guam Preservation Trust (GPT, a semiautonomous entity) and the Bank of Guam. The Guam Preservation Trust's mission is to preserve Guam history and Chamorro culture. Funded by building permit fees, GPT acquires a sizable budget that enables it to fund projects like Guampedia. As Guam's local bank, the Bank of Guam has demonstrated leadership in funding projects promoting Chamorro culture. Bank of Guam president Lou Leon Guerrero also sits on both the Guam Humanities Council and Guampedia Foundation's board of directors. To help establish the organisation, Guampedia received an appropriation (and is expecting another) from the government of Guam.

As island visitors are among Guampedia's target audiences, it received a smaller grant from the Guam Visitors Bureau. Guam visitor surveys document a strong desire by tourists for more historical and cultural information about the island. An online encyclopedia, freely accessible via the internet, enhances the visitor experience by providing a deeper and broader understanding about the destination.

\section{Development tales}

Once the first funding arrived, Guampedia immediately set about developing online encyclopedia content. Computers were purchased and two more editors - one to handle text and another to control media issues - were hired. At the same time, Guampedia contracted software designers who estimated it would take nine months to a year to develop the 'back-end' software that was needed at the time. In the year the software was being developed, Guampedia prepared its first 350 entries.

At first, Guampedia used what I call a 'scattershot' approach. This entailed asking dozens of people to write entries on a wide variety of topics, sending them contracts, setting deadlines and determining fees for their work. In hindsight, it would have been better to have taken a step-bystep approach, deciding, for example, to work on a single time period, or two or three topics at a time, so that the development process would be more focused. The Guampedia staff found that even strong project supporters and dedicated professionals need to be regularly reminded that promised entries were due - otherwise, many of them would or did not submit the entries they had agreed to write. The Guampedia Foundation understands that islanders are busy and have many other obligations besides contributing to Guampedia. Additionally, some contributors were unable to recognise Guampedia's importance before it went online. The Guampedia staff spent a lot of time following up on entries and learned the fine art of petitioning and pleading.

The Guampedia media editor set about identifying historic photograph collections and gaining permission to use them for illustrating the Guampedia entries. This was no easy task, as many community members did not want to share their photos and artwork. Eventually, once it was understood that their display was strictly for educational purposes, most allowed Guampedia to use the photos and illustrations.

Finally, when our carefully set deadlines had come and gone, when the software was completed and it was nearly time to go online, dozens of entries scheduled to be submitted months before were submitted at the last minute, written in a wide variety of styles. Launching the site was delayed for six months in order to spend needed time editing, fact-checking and peer-reviewing the late entries before including them. Once Guampedia felt comfortable with the accuracy of the content, the foundation went full speed ahead to publish the site online. 


\section{Testimonials}

A Chamorro man wrote to us from the eastern United States asking for help with his daughter's marriage preparations. He knew that part of the Chamorro Catholic wedding ceremony had to do with coins, but he could not remember exactly what it was. We contacted a priest who described the ceremony and what the priest, bride and groom were to say and sent it to the man, who was enormously grateful for the information.

Among many other issues, others have asked our staff for translations from Chamorro, for information on where to find a particular historic book, or to verify some bit of information. One woman asked to find the prayers for a novena her mother used to say so that she could continue the tradition. A student needed help finding information about Chamorro children's games for his presentation. We try to answer each one of the queries as best we can.

Recently, a cable television show producer contacted Guampedia for ghost stories to be used in an upcoming series on the supernatural. His crew loved it when we informed him about our taotaomona (ancestral spirits, see Bevacqua 2010). They spent a week on the island interviewing people and filming sites.

The community has embraced Guampedia. Guam's governor and senators have shared with the Guampedia Foundation that the online encyclopedia has helped them because whenever people ask for information about Guam, from the history of the Guam hymn or flag, to the schedule of village fiestas, they tell them to access Guampedia. Guampedia is being used by middle and high-school students for their homework projects, by college students for papers and presentations, and by teachers when preparing lessons relevant to Guam's history, art, culture and economics.

Many military personnel have written to let us know that Guampedia helped them learn about their new home. Likewise, business people and new contract hires have told us that it helped them to understand Guam better before taking a job on island. Guampedia has also helped the artists, musicians, dancers and community organisations featured in the online encyclopedia, as the public can easily find out about their work and contact them.

\section{The next steps}

Beginning in 2009, Guampedia worked with the Micronesian Area Research Center (MARC) and local archaeologists to build up Guampedia’s Ancient Guam section, an effort supported by funding from the Guam Preservation Trust. Many of MARC's research and publications describe Guam history after European contact and settlement of the Mariana Islands that began with the Spanish in about AD 1668. In contrast, there has been little knowledge collected, organised and presented in a readable format from the hundreds of archaeological reports (the grey literature) describing and discussing Chamorro settlement of the Mariana Islands nearly 4000 years ago. Guampedia set about to rectify this discrepancy.

Chamorro society passed information along orally rather than in written text during more than three millennia of pre-contact settlement history. Hence, the most comprehensive information concerning these early times is found in the archaeological record. Archeologists can inform the public about ancient Chamorro diets, fishing practices, pottery making, diseases and health, settlement patterns and burials, based on findings from ancient villages, agricultural fields, activity areas and other archaeological sites. Chamorro scholars privy to traditional narratives that have been passed down through the generations will be consulted to gain their understanding of these times and practices. Guampedia scheduled a year for the writing and editing of this new section. The final entries will provide Guam's communities with 
much important information about its ancestral population and environment from the time the island was first colonised until Padre Luis San Vitores arrived and Spain began inhabiting the archipelago in AD 1668.

Using maps and an interactive timeline, Guampedia also proposes to show which villages and settlements are known to have been inhabited 3000, 2000, 1000 and 500 years ago. For each of these timeframes, Guampedia users will be shown a map of Guam that pinpoints where archaeological sites have been identified. Users will be able to click on some of the sites to learn what life was like in that location at that time. Photographs, drawings and maps will illustrate some of these entries.

New ideas for categories, sub-sections and topics are constantly being suggested by community members. Guampedia will continue to evolve, as it must, to survive and keep up with new technology and ways of engaging a variety of audiences. For instance, Guampedia now has a presence on Facebook and Twitter, where followers can easily be led to new additions and relevant timely topics. Encyclopedia entries treating subjects that can become dated have a feature that notifies editors within a specified timeframe that the information needs to be reviewed.

The work of Guampedia is a monumental mission. There are times when it seems that there are too many tasks to accomplish or too many difficulties in securing funding. And the Guampedia vision keeps growing. With the help of local community members, Guampedia will continue to meet its goal of better informing the island population and the world about Guam and the Chamorro people.

\section{Note}

1. Founded in 1996, the National Initiative for a Networked Cultural Heritage (NINCH) is a US-based coalition of some 100 organisations and institutions from across the cultural sector. NINCH's objective is to build a framework within which these different elements can effectively collaborate to build a networked cultural heritage. 


\section{References}

Bevacqua, M.L. 2010. Taotaomo'na, (C) 2009 Guampedia $^{\mathrm{Tm}}$. Referenced January 20, 2011. http:// guampedia.com/taotaomona-taotaomona/.

Eclavea, G.E. 2010. Adoption of “Guamanian”. (C) 2009 Guampedia $^{\text {Tx. }}$ Referenced January 20, 2011. http://guampedia.com/adoption-of-guamanian/.

Goetzfridt, N. 2006. GUAMPEDIA: A work of legitimacy. Micronesica 5(1/2):340-344.

The Guam Humanities Council. 2004. Guampedia author project manual. Hågatña, Guam. 